Revista Destaques Acadêmicos, Lajeado, v. 9, n. 4, 2017. ISSN 2176-3070 DOI: http://dx.doi.org/10.22410/issn.2176-3070.v9i4a2017.1669 www.univates.br/revistas

\title{
DESENVOLVIMENTO E EXECUÇÃO DO APARATO DE PROTEÇÃO AO OVO
}

\author{
Aline Patrícia Hunemeier ${ }^{1}$, Maria Vitória Rempel ${ }^{2}$
}

Resumo: Com o objetivo de desafiar os alunos do curso de Engenharia Civil da Universidade de Vale do Taquari - UNIVATES na área de estruturas de concreto armado, foi realizada a primeira competição do Aparato de Proteção ao Ovo (APO) na instituição de ensino superior, que ocorreu durante o $11^{\circ}$ Congresso de Ciência e Tecnologia do Vale do Taquari (CCTEC). Este APO foi desenvolvido com o propósito de suportar o maior número de cargas possíveis e ter uma baixa deformação. Para sua confecção foi utilizado o cimento $C P \mathrm{~V}$, sílica ativa, areia de granulometria até $0,15 \mathrm{~mm}$, areia de até $0,30 \mathrm{~mm}$, pedriscos de até $9,5 \mathrm{~mm}$, água e fibra de polipropileno. Juntamente com a estrutura foram moldados dois corpos de prova, para posteriormente conhecer suas resistências através do ensaio de compressão. No dia da competição, o aparato de proteção ao ovo foi rompido, resistindo a 3 golpes. Os dois corpos de prova realizados e rompidos no mesmo dia do APO obtiveram as resistências de 33,40MPa e 30,94MPa.

Palavras-chave: Aparato de Proteção ao Ovo. Concreto armado. Pórtico. IBRACON.

\section{INTRODUÇÃO}

O aparato de proteção ao ovo (APO) é um dispositivo constituído por concreto armado que é submetido a um ensaio de carga dinâmica com o objetivo de apresentar resistência suficiente para proteger um ovo cozido sob a estrutura.

O ensaio realizado consistiu na queda de um cilindro de 15 quilogramas sobre o pórtico posicionado e fixado no gabarito, de modo a aumentar a altura de queda a cada impacto enquanto o ovo permanecesse intacto.

Para a confecção do aparato, utilizou-se o regulamento fornecido pelo Instituto Brasileiro do Concreto (IBRACON), o qual apresentava normas para inscrição e participação, materiais permitidos, explicação do ensaio e dimensões estabelecidas.

1 Graduanda em Engenharia Civil. Universidade do Vale do Taquari UNIVATES.

2 Graduanda em Engenharia Civil. Universidade do Vale do Taquari UNIVATES 
Durante o desenvolvimento do projeto, buscaram-se alternativas e materiais que pudessem aumentar a resistência do aparato, tais como a sílica e os aditivos, procurando neste aspecto, ampliar os conhecimentos e evoluir de forma significativa, de modo a gerar contribuição tanto na vida acadêmica, quanto na vida profissional.

A ruptura do aparato de proteção ao ovo ocorreu no $11^{\circ}$ Congresso de Ciência e Tecnologia do Vale do Taquari, (CCTEC) no dia 06 de outubro de 2017. O evento, promovido pela Universidade do Vale do Taquari - Univates, contou com a presença de todas as equipes que confeccionaram as estruturas.

\section{MATERIAIS E MÉTODOS}

\subsection{MATERIAIS}

Os materiais utilizados para a confecção do APO e suas características, atendendo aos requisitos exigidos pelo regulamento da competição, apresentam-se na Figura 1.

Figura 1 - Materiais utilizados para a confecção do concreto

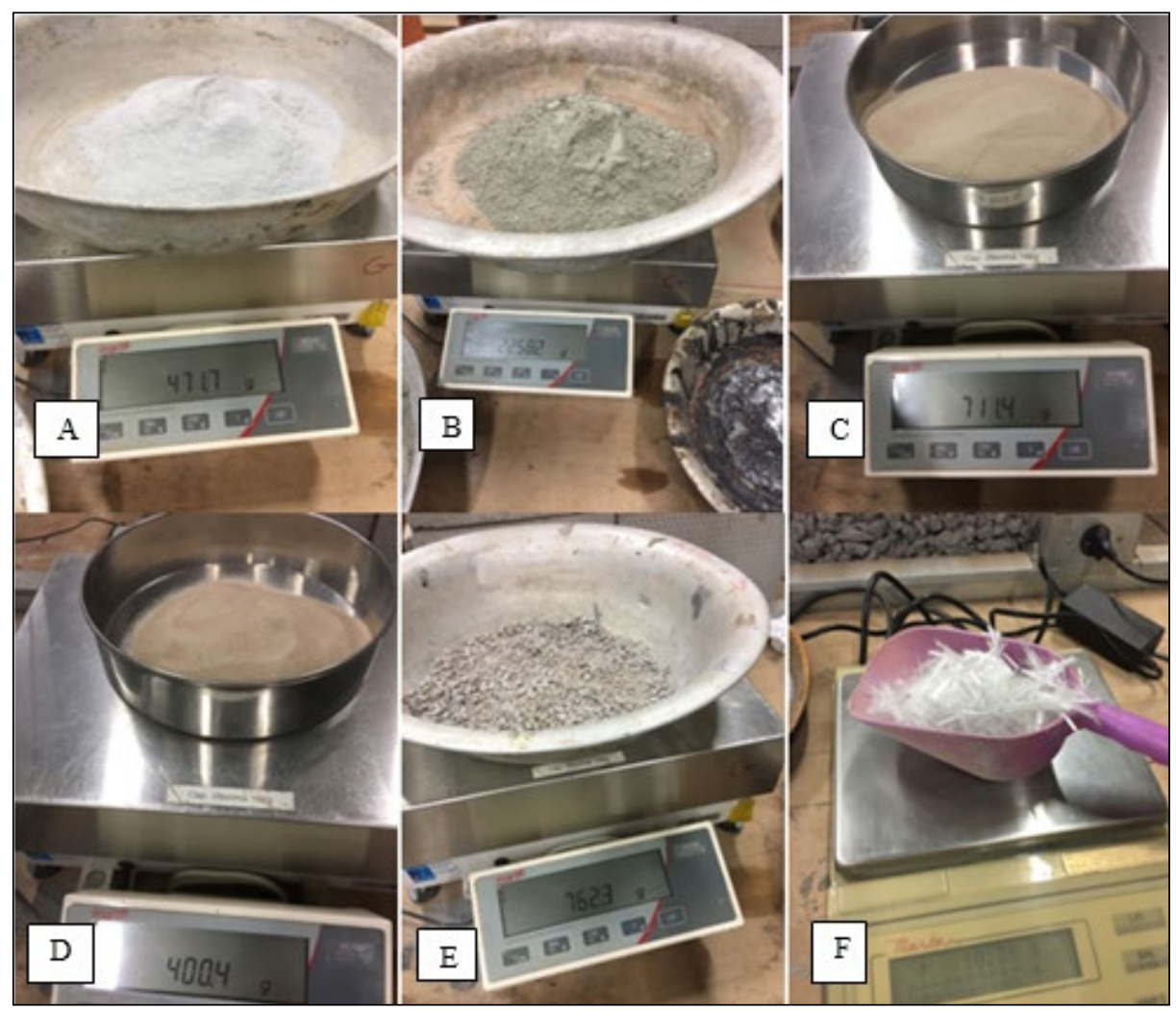

Fonte: Autoras (2017). 
Na Figura 1 é observado os materiais utilizados para o traço do concreto, sendo estes representados individualmente. Onde a letra " $\mathrm{A}$ " é a sílica ativa, " $\mathrm{B}$ " o cimento, " $\mathrm{C}$ " a areia de granulometria até $0,15 \mathrm{~mm}$, " $\mathrm{D}$ " a areia de até $0,30 \mathrm{~mm}$, "E" o agregado graúdo de até 9,5 mm e " $F$ " a fibra de polipropileno.

\subsubsection{Aço}

O aço escolhido para a concepção da armadura longitudinal foi o aço mola número 16, que apresenta diâmetro de $1,65 \mathrm{~mm}$. Já o material utilizado para a armadura transversal, foi o arame galvanizado número 19, com diâmetro de $1,07 \mathrm{~mm}$.

\subsubsection{Aditivos}

Os aditivos utilizados na confecção do APO foram o Reoplast PCE, um superplastificante tipo II à base de policarboxilato, que, de acordo com o catálogo do fornecedor, possui um grande poder de dispersão, proporcionando um concreto com alta resistência inicial e final e com excelente trabalhabilidade e o Buildermix MD, um plastificante polifuncional que aumenta a trabalhabilidade e permite reduzir a água de amassamento; também é utilizado para aumentar a fluidez, atingir resistências à compressão mais elevadas e reduzir o consumo de cimento segundo o catálogo do produtor.

\subsection{3 Água}

A água utilizada é proveniente da empresa Corsan responsável pelo abastecimento de água no munícipio de Lajeado/RS.

\subsubsection{Areia}

Foram utilizadas duas areias com diferentes granulometrias para a mistura do concreto, uma com o granulometria de até $0,15 \mathrm{~mm}$ e a outra até $0,30 \mathrm{~mm}$. Ambas finas para possibilitar que o concreto gerado tivesse a menor quantidade de vazios possíveis, proporcionando assim maiores resistências.

\subsubsection{Cimento} empresa Cimpor.

O cimento utilizado para a confecção do concreto foi o CP V ARI da

\subsubsection{Desmoldante}

O desmoldante utilizado foi fornecido pelo Laboratório de Tecnologias da Construção, LATEC, localizado no prédio 17 da Univates. 


\subsubsection{Fôrma}

Para a confecção da fôrma, o material utilizado foi a madeira compensada feita com placas finas de entalhos de madeira. As camadas são unidas umas às outras cada uma com seu grão perpendicular à camada adjacente para proporcionar maior força e resistência.

A madeira foi o único material a ser adquirido para a realização do APO, pois todos os demais materiais foram disponibilizados pelo LATEC.

\subsubsection{Agregado Graudo}

O agregado graúdo adotado para execução dos ensaios foi a brita 0 que, conforme o Ministério de Minas e Energia (MME) tem sua granulometria na faixa de $4,8 \mathrm{~mm}$ a $9,5 \mathrm{~mm}$

\subsubsection{Sílica Ativa}

De acordo com a TECNOSIL (2017), a utilização da sílica ativa no concreto proporciona baixa porosidade, maior resistência mecânica, maior aderência entre a pasta e armadura, e pasta e agregados. Por conta destas propriedades utilizou-se a sílica ativa neste traço, pois além da alta resistência, é preciso que ocorra uma perfeita aderência entre os fios de aço e o concreto, principalmente pelo aço ser de pequeno diâmetro e não apresentar ranhuras em sua superfície, característica que auxilia na aderência. As partículas da Sílica Ativa são esféricas, vítreas e possuem um diâmetro médio menor do que $1 \mu \mathrm{m}$.

\subsubsection{Fibra de Polipropileno}

Para a determinação da fibra a ser utilizada no APO, buscou-se encontrar uma fibra que proporcionasse uma maior resistência ao impacto, considerando que a estrutura sofreria aplicação de cargas dinâmicas. A partir disto, foi utilizada a fibra de polipropileno, pois de acordo com a NTC Brasil, 2017, ela apresenta propriedades que reduzem as fissuras por retração, e aumentam a resistência a impacto do concreto, atingindo assim o objetivo estipulado para a fibra.

\subsection{MÉTODO} seguir:

Para a realização do trabalho foram seguidos os passos determinados a

- Determinação do traço de concreto;

- Determinação dos modelos de armaduras a serem adotados;

- Confecção da fôrma de madeira;

- Corte e dobra das armaduras; 
- Concretagem;

- Desforma;

- Cura;

- Ruptura.

\subsubsection{Determinação do traço de concreto}

O APO é realizado com o intuito de resistir a cargas dinâmicas, buscando sempre seu melhor desempenho. Para a determinação do traço de concreto, optou-se pela utilização de fibras, com o propósito de melhorar as propriedades do concreto na resistência a cargas de impacto.

O traço inicial adotado foi de 1:0,23:0,33:0,18:0,39:0,03:0,19, sendo respectivamente representados por cimento $\mathrm{CP} V$, sílica ativa, areia de granulometria até $0,15 \mathrm{~mm}$, areia de até $0,30 \mathrm{~mm}$, agregado graúdo de até 9,5 $\mathrm{mm}$, aditivo superplastificante e água. Como pode-se perceber, a fibra não consta no traço, pois esta foi adicionada aos poucos durante a concretagem e observada a consistência adquirida pelo concreto.

Observa-se que o traço deste concreto é composto por materiais finos, com pequeno diâmetro das partículas. Buscou-se realizar um concreto com estas características, pois a estrutura é um pórtico de pequenas dimensões, sendo assim, possuindo pouco espaçamento entre as armaduras. Com um concreto mais fino, aumenta a probabilidade que ocorrerá um bom adensamento e não haverá vazios de concretagem, o que impactam drasticamente na redução da resistência mecânica.

\subsubsection{Determinação da armadura}

Para a realização da armadura do aparato de proteção ao ovo, procurouse, inicialmente, atender aos requisitos exigidos pelo edital do IBRACON, o qual determinava até 8 unidades de fios de aço a serem utilizados para armadura longitudinal, sendo seu diâmetro máximo de $1,65 \mathrm{~mm}$, e que fossem dispostos por todo pórtico sem emendas ou ondulações. Para a armadura transversal, seriam permitidos até 10 estribos com diâmetro máximo de $1,2 \mathrm{~mm}$. 
Figura 2 - Forma com armadura montada

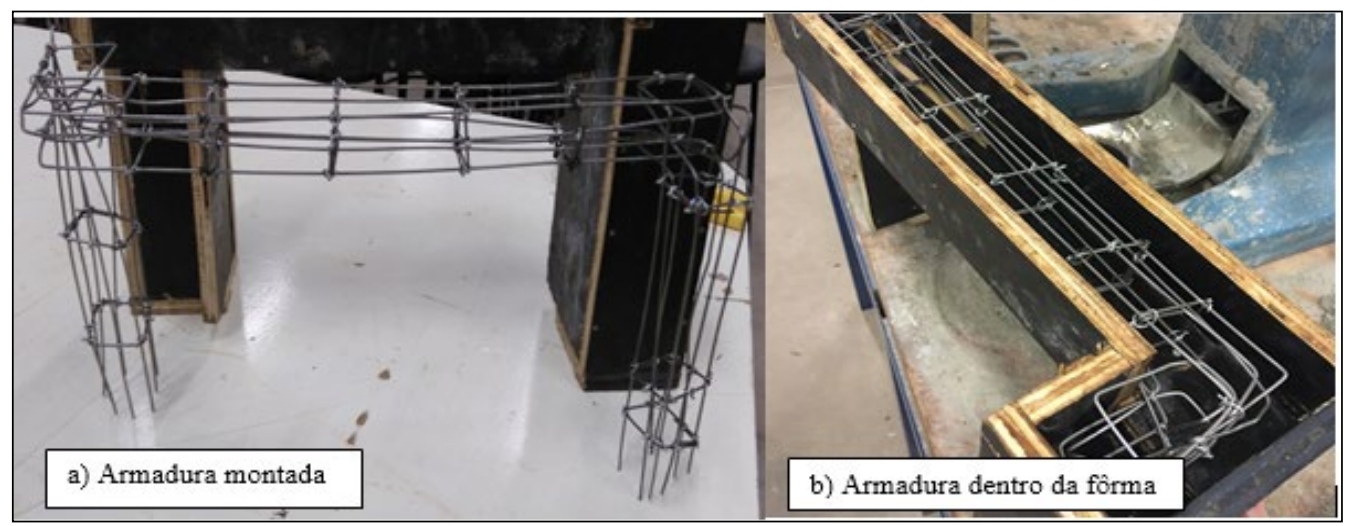

Fonte: Autoras (2017).

\subsubsection{Confecção da fôrma}

Com o traço e a armadura a serem utilizados determinados, houve a confecção da fôrma de madeira para o APO. Esta fôrma foi executada com compensado. A fôrma deveria ser feita com precisão, pois ela determinaria as dimensões finais do APO, e este, se não estivesse de acordo com o edital, poderia ser desclassificado.

Figura 3 - Vista frontal e superior da fôrma do pórtico

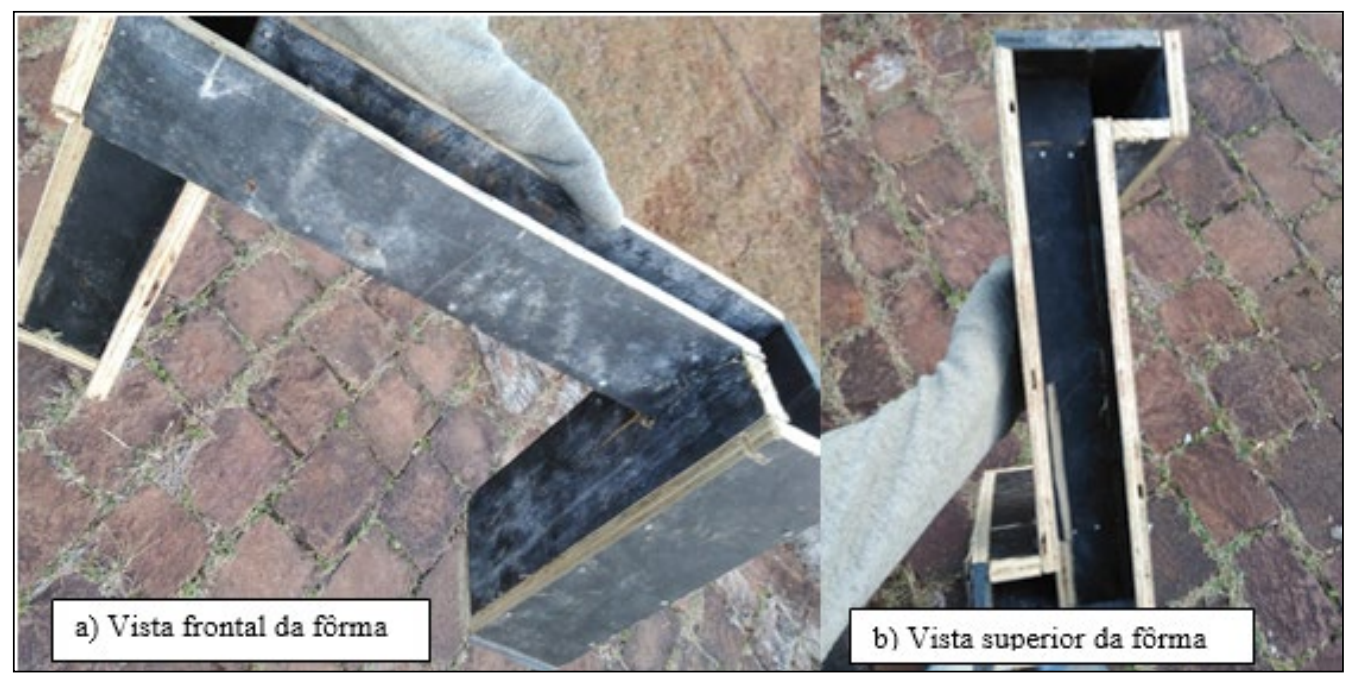

Fonte: Autoras (2017). 
Na Figura 3 observa-se a dimensão do pórtico, sendo sua altura total de $25 \mathrm{~cm}$, comprimento externo de $40 \mathrm{~cm}$, e seção interna dos dois pilares e da viga de $5 \times 5 \mathrm{~cm}$.

\subsubsection{Concretagem e cura}

A concretagem foi realizada em laboratório com a utilização de uma argamassadeira. Foram depositados todos os materiais, pouco a pouco, no recipiente até o adensamento correto do concreto, que foi colocado na fôrma com a armadura já posicionada e, posteriormente, adensado no adensador vibratório, conforme ilustra a Figura 4.

Figura 4 - Fôrma posicionada no adensador vibratório

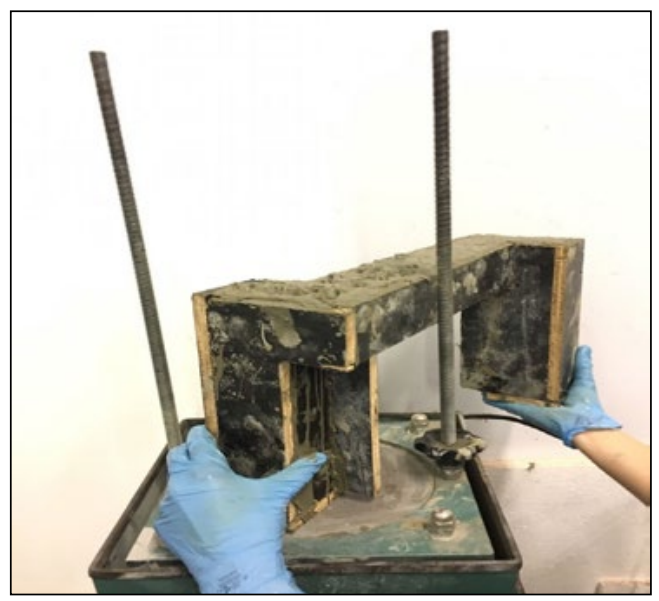

Fonte: Autoras (2017).

Durante a concretagem, foi realizada a mistura de dois aditivos, sendo eles o Reoplast PCE e o Buildermix MD, pois houve a utilização do material disponibilizado pela Universidade e, desta forma, não havia a quantidade necessária do aditivo adotado no traço inicial do concreto.

Por conta da argamassadeira não suportar todo o volume de concreto a ser realizado em uma única mistura, a mesma foi realizada em duas etapas. $\mathrm{O}$ aditivo ideal para as duas misturas foi inserido todo na primeira, desta forma, a dosagem do mesmo dobrou em relação ao previsto no traço.

Com o concreto pronto e vibrado na fôrma, este foi colocado na câmara úmida com temperatura controlada de $23^{\circ} \mathrm{C}$, com variação permitida de $( \pm) 2^{\circ} \mathrm{C}$ e umidade não inferior a 95\% para sua cura; sendo a retirada da fôrma prevista para dois dias após a concretagem. Com a passagem dos dois dias, percebeuse que o concreto ainda apresentava-se em estado fresco, motivo causado pelo excesso de aditivo na mistura. 
Com o concreto ainda fresco, tomou-se a decisão de retirá-lo da fôrma com cuidado para não danificar a fôrma e a armadura, e optou-se por realizar a concretagem novamente. Para isto, repetiu-se o mesmo traço inicial, apenas não havendo a adição de nenhum tipo de aditivo, sendo a fibra novamente adicionada aos poucos durante o adensamento, de forma que os passos da vibração foram novamente seguidos. Juntamente com o APO, foram moldados dois corpos de prova a serem rompidos ambos no mesmo dia do pórtico para poder determinar a resistência de compressão atingida. Um dos corpos de prova moldados está representado na Figura 5 a seguir.

Figura 5 - Corpo de prova moldado para verificação da resistência

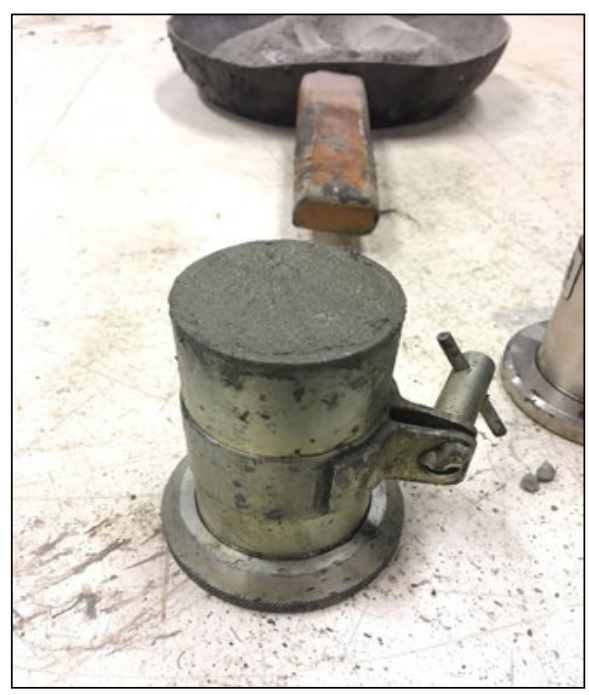

Fonte: Autoras (2017).

Após os dois dias da nova concretagem, retirou-se o APO da câmara úmida e verificou-se que, desta vez, ele estava em seu processo normal de cura, sendo assim possível realizar a desenforma e continuar com o processo de cura na câmara úmida até 2 dias antes da ruptura do pórtico.

O tempo ideal de cura da estrutura seria de 28 dias, pois a partir desta data, a resistência do concreto estabiliza. Como a primeira concretagem não ocorreu de maneira esperada e foi necessário realizar uma nova concretagem, seu tempo de cura real ficou em 21 dias, sendo assim, o pórtico ainda não havia obtido sua resistência ideal. Durante estes 21 dias de cura, em 19 deles o APO foi mantido com umidade e temperatura controlada.

Desta forma, a estrutura foi retirada da câmara úmida dois dias antes de sua ruptura para garantir que ela estivesse seca durante a aplicação da carga, possibilitando assim que suporte maior carga. 


\subsubsection{Ensaio}

O ensaio de carga dinâmica consiste na queda de um cilindro metálico com massa de 15 quilogramas sobre o pequeno pórtico de concreto armado, com aumento progressivo da altura de queda, iniciando em 1,0 metros. Se o APO resistisse ao primeiro impacto, dava-se seguimento ao ensaio, promovendo a segunda queda do cilindro de uma altura de 1,5 metros e assim sucessivamente, até a altura máxima de queda de 2,5 metros, de forma que enquanto o ovo ou a estrutura permanecessem intactos, prosseguiam-se as quedas da altura limite.

Inicialmente o aparato foi posicionado sobre o gabarito, mas, infelizmente, uma das extremidades não encaixou perfeitamente, devido ao fato de moldar o pórtico duas vezes e a fôrma ter estufado; mesmo assim, o pórtico foi fixado com elásticos sob um cano de PVC, onde estava inserido o cilindro metálico com massa de 15 quilogramas. Na Figura 6 pode-se observar que o encaixe não ocorreu perfeitamente no local do número 2 pintado na base.

Figura 6 - Aparato de Proteção ao Ovo posicionado para execução do ensaio

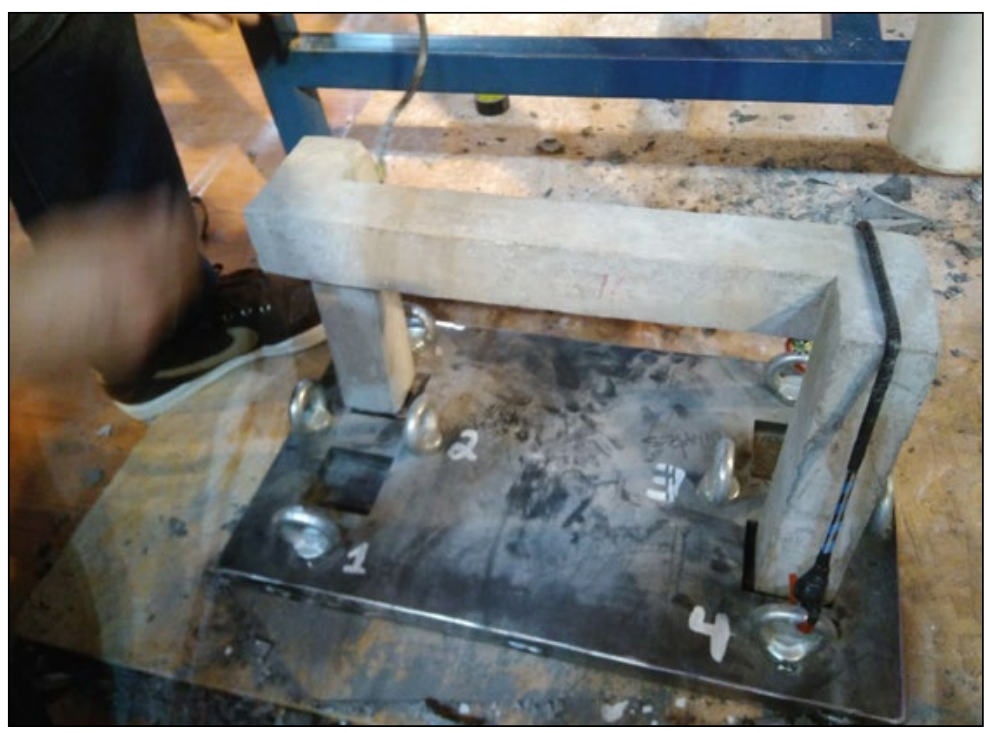

Fonte: Autoras (2017).

\section{CONSIDERAÇÕES FINAIS}

O APO confeccionado resistiu bem ao primeiro impacto, abrindo fissuras somente no segundo impacto, mas mantendo o ovo protegido. No terceiro impacto, a uma altura de 2,0 metros, a estrutura se rompeu completamente e o ovo foi esmagado. Na Figura 7 a seguir, pode-se observar como ficou a aparência final do pórtico após o ensaio. 
Figura 7 - Aparato de Proteção ao Ovo rompido

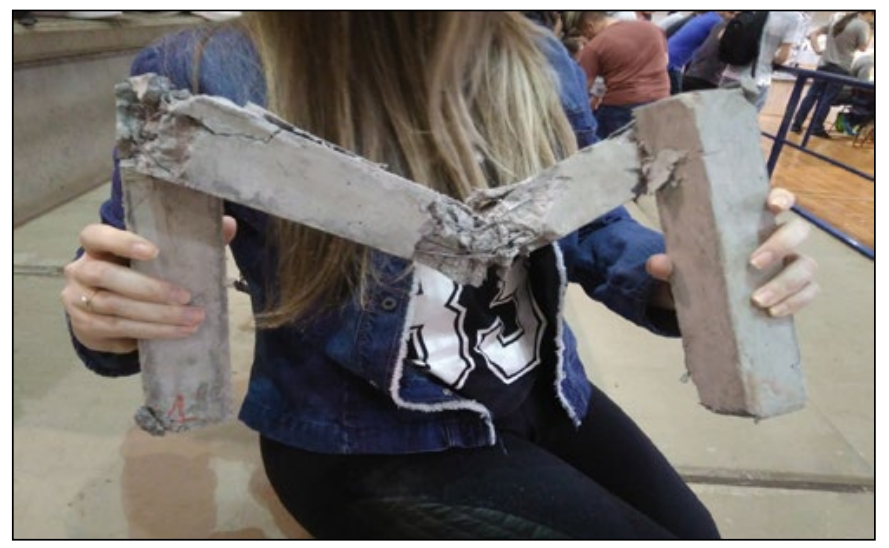

Fonte: Autoras (2017).

Os dois corpos de prova realizados com o primeiro traço e rompidos no mesmo dia do APO obtiveram as resistências de 33,40MPa e 30,94MPa. É possível verificar que a resistência de ambos foram bem similares, podendo assim afirmar que a resistência adquirida pelo APO rompido foi próxima a estes valores.

O baixo desempenho ocorreu devido ao pórtico não ter encaixado bem na base, ficando desta forma solto; motivo pelo qual houve a desclassificação da equipe, onde permitiu-se a realização do ensaio, mas sem possibilidade de competir com as demais equipes. Outro fator determinante foi à mudança do traço inicial, onde se retirou o aditivo e o tempo de cura que foi reduzido, não atingindo o tempo ideal dos 28 dias.

\section{REFERÊNCIAS}

ABCP. Cimento Portland CP V ARI Alta Resistência Inicial. Disponível em:<http:/ / www.abcp.org.br/cms/perguntas-frequentes/cimento-portland-cp-v-ari-altaresistencia-inicial-nbr-5733>. Acesso em 10 nov. 2017.

BUILDER. Produtos. Disponível em:<http://www.builder.ind.br/site/resultado_ produtos>. Acesso em 10 nov. 2017.

CIMENTO ITAMBÉ. Adicionar água suplementar ao concreto exige cuidados.

Disponível em:<http://www.cimentoitambe.com.br/adicionar-agua-suplementar-aoconcreto-exige-cuidados>. Acesso em 20 nov. 2017.

MME. Perfil de brita para construção civil. Disponível em:< http://www.mme.gov. br/documents/1138775/1256650/P22_RT30_Perfil_de_brita_para_construxo_civil. pdf/01c75ac7-ecd2-4d85-a127-3ecddecb2a31>. Acesso em 22 nov. 2017. 
NTC BRASIL. Fibras de Polipropileno. Disponível em:<https://www.ntcbrasil.com. br/blog/fibras-de-polipropileno/>. Acesso em 21 out. 2017.

TECNOSILBR. Catálogo Sílica Ativa. Disponível em:<http:/ /www.tecnosilbr.com. $\mathrm{br} / \mathrm{wp}$-content/themes/tecnosilbr/download/catalogo-silica-ativa.pdf $>$. Acesso em 29 out. 2017. 